\title{
Mapeamento de práticas violentas como dispositivo de intervenção da psicologia na escola
}

\author{
Mapping of violent practices as an intervention device of psychology at school
}

\author{
Irme Salete Bonamigo ${ }^{[a]}$, Celso Francisco Tondin ${ }^{[b]}$, Francieli Bortolossi ${ }^{[c]}$, \\ Karina Paula Seraglio ${ }^{[d]}$, Daniela Fernanda Schott ${ }^{[e]}$, Maxemino Martinelli ${ }^{[t]}$
}

\footnotetext{
[a] Psicóloga, Doutora em Psicologia Social pela Universidade do Estado do Rio de Janeiro (UERJ), professora do mestrado em Políticas Sociais e Dinâmicas Regionais e do curso de Psicologia da Universidade Comunitária da Região de Chapecó (Unochapecó), Chapecó, SC - Brasil, e-mail: bonamigo@unochapeco.edu.br

${ }^{[b]}$ Psicólogo, mestre em Psicologia pela Universidade Federal de Minas Gerais (UFMG), doutorando em Psicologia da Pontifícia Universidade Católica do Rio Grande do Sul (PUCRS), professor da Universidade Comunitária da Região de Chapecó (Unochapecó) Chapecó, SC - Brasil, e-mail: tondin@unochapeco.edu.br

${ }^{[c]}$ Estudante do curso de Psicologia da Universidade Comunitária da Região de Chapecó (Unochapecó) Chapecó, SC - Brasil, e-mail: bortolossi@unochapeco.edu.br

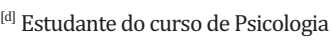
da Universidade Comunitária da Região de Chapecó (Unochapecó), Chapecó, SC - Brasil, e-mail: nynna@unochapeco.edu.br

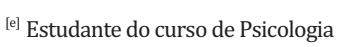
da Universidade Comunitária da Região de Chapecó (Unochapecó) Chapecó, SC - Brasil, e-mail: danischott@unochapeco.edu.br

[f] Estudante do curso de Psicologia da Universidade Comunitária da Região de Chapecó (Unochapecó) Chapecó, SC - Brasil, e-mail: maxemino@unochapeco.edu.br
}

Recebido: 29/10/2010 Received: 10/29/2010

Aprovado: 17/03/2011 Approved: 03/17/2011

\section{Resumo}

Este artigo discute o tema violências e escola, com base em pesquisa de levantamento realizada em 13 escolas públicas estaduais de Chapecó (SC), por meio da aplicação de questionário a 693 estudantes do ensino fundamental e médio, 147 professores e 123 famílias. São apresentadas as percepções dos participantes quanto à existência de agressões verbais, ameaças, agressões físicas, assédio sexual, danificação do patrimônio escolar, uso e tráfico de drogas, furtos e presença de aluno armado. A presença das práticas violentas no espaço escolar foi investigada nas relações entre alunos, alunos e professores, alunos e funcionários e professores/ funcionários e familiares. Os dados analisados destacam a presença significativa de agressão verbal, ameaças, agressões físicas leves e furtos, entre alunos; danificação e furto de materiais e equipamentos da escola e apontam a existência menos frequente de agressões verbais e ameaças entre alunos e professores. Os resultados da pesquisa possibilitam identificar a necessidade de realização de pesquisas complementares para investigar singularidades presentes em cada escola, no que diz respeito às violências mapeadas. Podem ser utilizados, ainda, como dispositivos de intervenção do psicólogo na escola, para mobilizar os diferentes atores e contribuir para a reflexão de questões que atravessam a comunidade escolar, como o desafio de construir relações de respeito e cooperação entre os seus membros e de criar dispositivos de socialização e educação que contemplem outros modos de lidar com o conflito.

Palavras-chave: Violência. Escola. Psicologia. Psicologia e educação. Psicologia escolar.

\section{Abstract}

This article discusses the issue of violence and school, based on a survey research made in 13 public state schools in Chapecó (SC). A questionnaire was and 693 students of basic and high levels, 147 teachers and 123 families answered it. Perceptions about the occurrence of verbal aggression, threats, physical aggression, sexual harassment, destruction of school items, use and traffic of drugs, thefts and presence of armed students are shown in this study. The occurrence of violent practices at school was investigated in relations between students and also between students and teachers, students and employees and teachers/employees and student family members. The analysed data indicate a significant occurrence of verbal aggression, threats, light physical aggression and thefts among students, damage and theft of school materials and equipment. 


\begin{abstract}
The data also show a smaller frequency of verbal aggressions and threats between students and teachers. The results of the research allow identifying the need to make additional studies in order to investigate the singularities of each school in what concerns to mapped ways of violence. That information may also be used as intervention devices by the school psychologist to mobilize different actors. It also contributes to think about the issues that cross school communities, such as the challenge of constructing relationships based in respect and cooperation among members and the creation of socialization and educational devices that contemplate alternative ways to deal with conflict.
\end{abstract}

Keywords: Violence. School. Psychology. Psychology and education. School psychology.

\section{Introducão}

As violências que acontecem na escola é um dos temas que atualmente preocupa pais, alunos e educadores. Essa preocupação aparece nas reportagens recorrentes da mídia impressa e eletrônica, nos comentários cotidianos e na demanda pelo trabalho do psicólogo para discutir e intervir frente a situações com presença de práticas violentas. Estudos já foram realizados em nível de Brasil (Abramovay \& Rua, 2002; Ruotti, Alves, \& Cubas, 2006; Santos, 2009; Paula \& D'Aurea-Tardeli, 2009), os quais identificaram e analisaram práticas violentas no espaço escolar, mas nenhuma pesquisa ainda havia sido desenvolvida tomando como cenário de estudo a cidade de Chapecó (SC).

O estudo teve como propósito conhecer as práticas violentas presentes nas escolas públicas estaduais de Chapecó de modo a contribuir com o exercício profissional do psicólogo no campo da Psicologia e Educação. 0 mapeamento das práticas violentas possibilitou maior conhecimento do fenômeno no município, podendo seus resultados serem utilizados como subsídio para a discussão do tema nas escolas pesquisadas e para o trabalho do psicólogo. Ainda, incentiva a realização de pesquisas complementares para aprofundar e ampliar a investigação sobre este objeto de investigação.

Com base em Michaud (1989, p. 10-11), consideram-se violentas as situações de interação, nas quais

um ou vários atores agem de maneira direta ou indireta, maciça ou esparsa, causando danos a uma ou a mais pessoas em graus variáveis, seja em sua integridade física, seja em sua integridade moral, em suas posses, ou em suas participações simbólicas e culturais.
Abordar este tema requer alguns cuidados, pois a expressão violência na escola abrange uma infinidade de significados e práticas heterogêneas. Charlot (2002) propõe fazer distinções conceituais entre violência $n a$ escola, violência à escola e a violência $d a$ escola. A primeira refere-se às violências que poderiam ocorrer fora dos portões da escola e não dizem respeito à instituição escolar, como, por exemplo, a invasão de um grupo para brigar com alguém no interior deste estabelecimento. A violência $\grave{a}$ escola engloba as práticas violentas direcionadas ao estabelecimento escolar, ou a quem os representa. E, ainda, a violência $d a$ escola abrange a violência institucional simbólica que os próprios alunos suportam por meio da maneira como a instituição e seus agentes os tratam. Para a autora, estas distinções possibilitam investigar e analisar os fenômenos cada qual em sua particularidade, sem delimitá-los e generalizá-los sob uma categoria.

É importante também considerar que as definições e sentidos atribuídos à categoria violência variam em função do estabelecimento escolar, do status de quem fala (professor, diretor, estudantes, entre outros), de suas vivências e percepções.

\section{Método}

Trata-se de pesquisa quantitativa, realizada a partir de levantamento de dados primários que abrangeu, como universo de pesquisa, escolas públicas estaduais situadas no município de Chapecó. Inicialmente, foram identificadas as escolas públicas estaduais da cidade (total de 22) e classificadas pelo número de estudantes em pequenas (até 650 alunos/ as), médias (de 651 a 960) e grandes (acima de 961). 
Em seguida, foi definida uma amostra estratificada das escolas e do número de participantes de cada escola, de modo a garantir uma participação proporcional dos diferentes grupos: pais, professores e alunos. Posteriormente, em cada escola, foi realizado sorteio aleatório dos participantes de cada grupo, considerando os três turnos do ensino fundamental e médio.

Com base nesses procedimentos, a pesquisa foi realizada em 13 escolas públicas estaduais de Chapecó, com 963 participantes: 693 estudantes do ensinos fundamental e médio, dos turnos matutino, vespertino e noturno, 147 professores e 123 famílias.

Utilizou-se o questionário como instrumento de pesquisa, o qual foi aplicado aos estudantes em sala de aula, aos professores para ser respondido e devolvido em data estabelecida, e aos pais foi enviado pelos seus filhos para que fosse respondido em casa e encaminhado à escola. 0 questionário continha o total de 32 questões: uma com resposta aberta, 26 com alternativas de múltipla escolha e cinco continham, além das alternativas de múltipla escolha, uma pergunta com resposta aberta.

Os tipos de violências pesquisadas foram: agressões verbais (xingamentos, deboches, ofensas, etc.), agressões físicas leves (chutes, socos, empurrões, tapas, etc.), agressões físicas com atendimento médico, ameaças, violência contra o patrimônio escolar (furtos, vandalismo, entre outros); assédio sexual (insinuações, contatos físicos forçados, comentários de ordem sexual que geram constrangimento, etc.) e delitos (uso de drogas, tráfico de drogas, consumo de álcool, furtos e presença de aluno armado). A presença das práticas violentas foi investigada nas relações entre alunos, entre alunos e professores, entre alunos e funcionários, entre professores/ funcionários e familiares.

O questionário ainda continha questões sobre violências e delitos nas proximidades da escola, equipamentos de segurança utilizados pela escola, presença da polícia no interior da escola e a relação entre escola e família. Perguntou-se ainda se havia ficado fora do instrumento alguma prática que o participante considerasse violenta e foi aberta a possibilidade de se fazer comentários sobre violência na escola.

As questões sobre a ocorrência de práticas violentas no interior da escola continham como resposta as alternativas "sempre", "às vezes", "raramente", "nunca", "não sabe". A questão sobre violências e delitos nas proximidades da escola permitia assinalar as respostas: tráfico de drogas, roubos, ação de gangues, agressões físicas, mortes, não ocorre, não sabe, outros (qual?). A pergunta sobre equipamentos de segurança existentes na escola arrolava as alternativas muros altos, grades, alarme, circuito interno de TV, presença de vigilante, não sabe, outro (descreva).

Os questionários foram aplicados por seis estudantes do segundo, quinto e sétimo períodos do curso de Psicologia da Unochapecó, uma bolsista e cinco voluntários/as, com a orientação de dois professores coordenadores e orientadores da pesquisa.

0 projeto de pesquisa foi aprovado pelo Comitê de Ética e autorizado pela Gerência Regional de Educação da Secretaria de Estado de Educação, pelos estabelecimentos e participantes da pesquisa. O questionário foi acompanhado de esclarecimentos sobre o estudo e do Termo de Consentimento Livre e Esclarecido. No caso dos estudantes menores de idade, foi assinado pelos pais ou responsáveis.

As informações resultantes da aplicação dos questionários foram tabuladas com o auxílio do programa Microsoft Office Excel e analisadas estatisticamente e com base na literatura produzida na área.

A restituição dos resultados às escolas pesquisadas e comunidades já está em processo de realização, por meio de encontros para discussão. Concebe-se a restituição, conforme Lourau (1993), como uma "atividade intrínseca à pesquisa", constituindo-se na devolução às pessoas participantes e às pessoas que vivem e produzem as práticas pesquisadas, o saber científico que elas permitiram construir.

\section{Se a população estudada recebe esta restituição, pode se apropriar de uma parte do status do pesquisador, se tornar uma espécie de 'pesquisador-coletivo', sem a ne- cessidade de diplomas ou anos de estudos superiores, e produzir novas restituições [...] Isto seria, efetivamente, a socialização da pesquisa (Lourau, 1993, p. 56).}

Compreende-se que, ao se fazer a devolução das informações produzidas, inicia-se um processo o qual pode ser continuado pela escola e comunidade envolvida, no que diz respeito aos movimentos de se colocar em análise as práticas cotidianas e se buscar mudanças que envolvam a reflexão e a ação dos diversos atores implicados em suas construções.

\section{Resultados}

Foi possível identificar, a partir da percepção dos estudantes, professores e pais, as práticas violentas 
mais presentes nas escolas. Destacaram-se quatro práticas violentas que, segundo os participantes, ocorrem sempre ou às vezes entre alunos. A agressão verbal entre alunos foi indicada por $88 \%$ dos estudantes, $83 \%$ dos professores e $78 \%$ dos pais. As agressões físicas leves entre alunos foram assinaladas por $81 \%$ dos estudantes, $73 \%$ dos professores e $68 \%$ dos pais. As ameaças entre alunos foram apontadas por $79 \%$ dos estudantes, $65 \%$ dos professores e $76 \%$ dos pais. Os furtos entre alunos foram destacados por $57 \%$ dos estudantes, $55 \%$ das famílias e $53 \%$ dos professores.

Ainda, classificaram-se entre as primeiras colocadas, a danificação do patrimônio da escola, que foi marcada por $73 \%$ dos estudantes, $70 \%$ dos professores e $83 \%$ das famílias, e a prática de furto de materiais e equipamentos da escola, a qual foi assinalada por $66 \%$ dos estudantes, $60 \%$ dos professores e $62 \%$ dos pais.

Foram apontadas também duas práticas violentas que ocorrem, "às vezes" e "raramente", entre alunos e professores. As agressões verbais entre alunos e professores foram destacadas como acontecendo "às vezes" por $41 \%$ dos estudantes, $50 \%$ dos professores e $47 \%$ das famílias e "raramente" por $30 \%$ dos estudantes, $27 \%$ dos professores e $24 \%$ das famílias. As ameaças entre alunos e professores acontecem "às vezes" para $29 \%$ dos alunos, $38 \%$ dos professores e $16 \%$ dos pais e "raramente" para $23 \%$ dos estudantes, $26 \%$ dos professores e $28 \%$ dos pais, e, para $21 \%$ dos pais, elas "nunca" acontecem.

$\mathrm{Na}$ percepção da população pesquisada, de modo um pouco menos frequente, ocorrem furtos entre alunos (35\% às vezes, $20 \%$ sempre e $22 \%$ raramente). A prática de furtos não é destacada nas relações entre alunos e professores e entre alunos e funcionários, nas quais as opções predominantemente assinaladas (61\%) são "nunca" e "não sabe".

Houve diferença de percepção entre pais, professores e estudantes quanto à existência de agressões físicas entre alunos com atendimento médico, enquanto que a maioria dos estudantes $(82 \%)$ e professores (83\%) assinalou que elas acontecem "raramente", "nunca" e "não sabe", somente $69 \%$ dos pais indicaram essas alternativas, e $17 \%$ apontou que a prática acontece "às vezes". Também houve diferença de percepção quanto à prática de assédio sexual entre alunos: enquanto que $49 \%$ dos estudantes e $45 \%$ das famílias responderam que "nunca" ocorrem e "não sabem", $27 \%$ dos professores afirmaram ocorrer "às vezes", 18\% "raramente", 12\% "nunca", e $29 \%$ "não sabem".

Uma parte significativa da população pesquisada respondeu que "não sabe" se o uso de drogas (39\%), o consumo de álcool (32\%) e o tráfico de drogas (45\%) acontecem dentro da escola, no entanto outra parte afirmou que o uso de drogas (29\%), o tráfico de drogas (29\%) e o consumo de álcool (36\%) "nunca" acontece na escola. Quanto à presença de aluno armado na escola, $38 \%$ respondeu que não há e 33\% que "não sabe".

Quanto à agressão física entre alunos e professores, $46 \%$ do total de participantes respondeu que "nunca" acontece, $20 \%$ que acontece "raramente", $12 \%$ "às vezes" e 14\% "não sabe". Em relação às ameaças entre alunos e funcionários, $65 \%$ marcou que elas "nunca" acontecem ou "não sabe" se acontecem e, entre professores e familiares, $17 \%$ assinalou que acontecem raramente e $67 \%$ que "nunca" acontecem ou "não sabe" se acontecem.

A maioria dos participantes assinalou que as práticas de agressão física entre alunos e funcionários (76\%), entre professores, funcionários e familiares (78\%) e o assédio sexual entre alunos e professores (76\%) "nunca" acontece ou "não sabe" se acontecem.

Quanto às proximidades da escola, foram apontadas como os tipos de violência mais comuns: agressões físicas (30\% estudantes, $25 \%$ professores e $31 \%$ pais), roubos (22\% estudantes, $19 \%$ professores e $17 \%$ pais), tráfico de drogas (19\% professores, $12 \%$ estudantes e $10 \%$ famílias) e ação de gangues (13\% famílias, $15 \%$ professores e $12 \%$ estudantes).

A maioria dos participantes afirmou que a presença da polícia na escola acontece raramente $(32 \%$ estudantes, $35 \%$ professores e $31 \%$ familiares) e "nunca" (32\% dos professores, $26 \%$ estudantes e $23 \%$ familiares). Os equipamentos de segurança destacados nas escolas foram: grades (31\% estudantes, $29 \%$ professores, $29 \%$ famílias), alarme (28\% professores, $22 \%$ estudantes, $19 \%$ família) muros altos $(18 \%$ estudantes, $18 \%$ família, $15 \%$ professores), presença de vigilante (18\% estudantes, $18 \%$ professores, $16 \%$ famílias).

Após a tabulação dos dados de cada escola com a produção de tabelas e gráficos, foi iniciado o processo de restituição das informações da pesquisa às escolas e comunidades que participaram da pesquisa. A restituição em andamento já aponta indícios de que o levantamento realizado é um importante 
dispositivo para a discussão sobre violências nas escolas, pois torna visíveis as percepções dos diferentes atores que compõem o seu cotidiano e problemáticas destacadas por eles.

\section{Discussão dos resultados}

Os questionários respondidos pelos estudantes, professores e pais permitem distinguir três tipos de práticas violentas presentes nas escolas: a) violências na escola: agressão verbal, agressões físicas leves e ameaças entre alunos; b) violências à escola: vandalismo e furto de materiais e equipamentos da escola, agressão verbal e ameaça de estudantes contra professores; c) violências $d a$ escola: agressões verbais e ameaças de professores contra alunos. Essa classificação contribui, conforme proposto por Charlot (2002), para analisar o papel da escola com relação às violências. Diante da ocorrência de violência na escola, a instituição escolar estaria mais impotente e dependeria de outros dispositivos vinculados à segurança pública e outras organizações sociais. Já diante da violência à escola e $d a$ escola, disporia de margens de ações diretas relacionadas à dinâmica das relações escolares e à organização escolar. No entanto, é necessário ir além desta classificação, pois não se pode correr o risco, principalmente no caso das violências na escola, de simplesmente atribuir a ação violenta aos estudantes, sem investigar e reconhecer de que maneira a escola participa da produção das violências a partir das suas práticas cotidianas.

Desse modo, discutir-se-ão as práticas violentas que mais se destacaram na pesquisa, em busca de elementos que contribuam para a compreensão de singularidades presentes em cada modo de expressão.

\section{Violências nas relacões entre alunos}

Na relação entre alunos, destacaram-se as agressões verbais, as ameaças e as violências físicas leves, que ocorrem "sempre" ou "às vezes". As agressões verbais abrangem comportamentos como xingamentos, deboches, ofensas, provocações, entre outros. Sebenello (2009, p. 34), em pesquisa realizada em uma escola pública de Chapecó, detectou esse tipo de agressão por meio da fala, como, por exemplo, "seu bosta, seu merda" e também por escrito, como a pichação que encontrou no banheiro feminino da escola: “T. 201. Puta, galinha, chifruda” (Sebenello, 2009, p. 35). Ruotti (2006), em pesquisa realizada em escolas públicas de São Paulo, também identificou agressões verbais entre alunos, as quais muitas vezes levavam às agressões físicas:

Os alunos relataram que algumas brigas que ocorreram durante o intervalo ou na entrada/saída da escola tiveram seus motivos gerados ainda em sala de aula: são provocações, discussões e xingamentos que geram o denominado 'acerto de contas', que envolve frequentemente agressão física (Ruotti, 2006, p. 96).

A ameaça entre alunos (promessa de causar algum tipo de dano ao outro) foi apontada pelos participantes da pesquisa como uma das práticas mais frequentes, aproximando-se das agressões verbais e das agressões físicas leves entre alunos. 0 mesmo ocorreu na pesquisa de Ruotti (2006, p. 71), indicando "uma tensão nas relações entre os alunos, os quais muitas vezes procuram resolver do lado de fora da escola desavenças criadas dentro da escola”.

Percebe-se como os três tipos de agressões entre alunos podem estar vinculados. Alves (2006, p. 122) sugere que "desestimular as agressões verbais pode ser uma forma de diminuir as agressões físicas entre alunos". 0 autor analisa que há uma expectativa de que o processo de socialização e educação de crianças e adolescentes reduza o uso de agressão para a solução de conflitos e aumente o uso de formas pacíficas. A escola é um dos espaços que contribui para desenvolver e aperfeiçoar o processo socializador e educativo, no entanto, "vários casos demonstram que tais comportamentos, além de não sofrerem redução ao longo do processo de escolarização, tornam-se, muitas vezes, ainda mais graves" (Alves, 2006, p. 121).

Muitas das consideradas atuais formas de violências entre os alunos eram até recentemente denominadas simplesmente de brigas e, na maioria das situações, tidas como parte do momento do desenvolvimento infanto-juvenil. Na atualidade, em uma sociedade que vive sob o medo da violência iminente, as agressões verbais, as ameaças e as violências físicas leves passam a ser consideradas como de grande potencial destrutivo ou "porta de entrada" para o mundo da violência mais grave. Uma reflexão crítica desse fenômeno nos indica que, do ponto de vista do alunado:

Na fronteira entre o abandono de toda e qualquer negociação de sentido para a sua escolarização e a 
incapacidade de abraçar completamente o 'sonho' de uma escola que os faça melhorar de vida, esses alunos são obrigados a refletir sua própria situação, e nessa busca tecem críticas contundentes que tocam fundo no caráter reprodutivo da escola. $\mathrm{O}$ abandono lento da escola é uma das faces dessa situação. A permanência burocrática, outra. A resistência e a busca pela ocupação dos espaços (físicos e simbólicos) da escola, a única possibilidade de sobrevivência nela (Peregrino, 2003, p. 229).

Essas considerações tornam visível a importância do papel da escola no processo socializador e educativo de crianças e adolescentes, sendo necessário que busque, no seu cotidiano, novos dispositivos de socialização e educação que privilegiem formas cooperativas de relação, mediadas pelo uso da palavra e do diálogo.

Para Santos (2001, p. 116), uma saída seria "incorporar o conflito como uma tensão positiva para a escola, como algo que pode criar coesão social", ou seja, a escola poderia assumir pedagogicamente o conflito como criador de relações sociais.

As situações de conflito trazem em si um potencial de mobilização das comunidades escolares. Nessa direção, Rocha (2000), a partir de uma abordagem institucionalista, sugere que o trabalho do psicólogo pode se dar nas "brechas" do sistema, porque, se por um lado, há um tédio nas escolas, vivido como impotência, fragilização e desinvestimento, por outro, existem conflitos, resistências e fraturas. E é nesta ineficiência do sistema que o psicólogo poderá contribuir para que a escola invente outros tempos/espaços, escutando as turbulências, as intensidades e as afecções entre os corpos. "0 grande desafio é transformarmo-nos não no interlocutor que discute as formas constituídas, mas no intercessor que faz alianças com as forças que se abrem para o inesperado" (Rocha, 2000, p. 194).

\section{Violências na relação entre alunos e professores}

Foram destacadas pelos participantes da pesquisa a agressão verbal e as ameaças que ocorrem "às vezes" e "raramente" na relação entre alunos e professores. Esta menor frequência também foi identificada pela pesquisa desenvolvida por Ruotti (2006) em escolas da zona leste e sul de São Paulo.

Sebenello (2009), ao investigar agressões verbais e ameaças entre alunos e professores, identificou que muitos professores não se sentiam respeitados pelos alunos e relataram que foram ofendidos por eles em sala de aula. No entanto, os alunos também afirmaram se sentirem agredidos: "Eles chamam a gente de burrinha, ignorante, essas coisas assim" (Sebenello, 2009 , p. 47). Alguns professores admitiram que algumas vezes agridem verbalmente estudantes:

porque tu entra em uma sala de aula e às vezes o pessoal está desorganizado, tem muita conversa, a gente já vem de anos assim de um trabalho bastante estressante, e chega um momento que às vezes você perde $a$ paciência [...] às vezes você usa também palavrões pra xingar eles (Sebenello, 2009, p. 47).

Alves (2006) afirma que, na ação educativa, a própria relação entre professor e aluno é potencialmente conflitiva, implicando diversos fatores, como o encontro de diferentes saberes e diferentes temporalidades. O desafio é como esses conflitos podem ser resolvidos e encaminhados a partir da própria ação pedagógica, antes que tomem o caminho da agressão.

É necessário ainda analisar que as agressões verbais e ameaças de professores contra alunos configuram práticas violentas da escola contra os alunos. Ansara e Costa (2009, p. 90) discutem que, em geral, na escola "predomina uma relação extremamente verticalizada, hierarquizada, autoritária e repressora". É comum gestores e docentes gritarem com os estudantes e os impedirem de manifestar opiniões. É importante também ressaltar que existem outras formas de violência da escola, que não foram investigadas pela presente pesquisa, como a violência institucional simbólica, citada por Charlot (2003, p. 435), que abrange "modos de composição das classes, de atribuição de notas, de orientação [...] atos considerados pelos alunos como injustos ou racistas".

No entanto, deve-se também considerar, como aponta Patto (2005), que os professores também são vítimas do descaso dos governantes, como, por exemplo, as más condições de trabalho, os baixos salários e a exclusão dos centros decisórios.

Souza (2006) afirma ainda que as principais políticas educacionais elaboradas a partir da década de 1990 apresentam um discurso de enfrentamento da exclusão social, no entanto a sua implementação, em geral, é marcada pelos seguintes pontos que as tornam, em grande medida, inadequadas para as realidades escolares: 
a) a manutenção de formas hierarquizadas e pouco democráticas de implementação das políticas educacionais;

b) a desconsideração da história profissional e política daqueles que fazem o dia a dia da escola;

c) a implantação de políticas educacionais sem a necessária articulação com a devida infraestrutura para sua real efetivação;

d) a manutenção de concepções a respeito dos alunos e de suas famílias, oriundos das classes populares, que desqualificam parcela importante da população para a qual estas políticas são dirigidas;

e) o desconhecimento das reais finalidades das políticas educacionais implementadas pelos próprios educadores;

f) o aprofundamento da alienação do trabalho pedagógico e a busca quase desumana de significado e sentido pessoal (Souza, 2006, p. 236).

Já nas agressões verbais e ameaças de alunos contra professores, está implicada também a agressão contra a própria escola. Essa atitude pode ser analisada como um modo de recusa, por parte dos estudantes, do conjunto de valores transmitidos pela instituição escolar, que não mais responde ao seu universo de necessidades no que diz respeito à ascensão e mobilidade social (Sposito, 1998). Além da agressão, o retraimento e a indiferença seriam outros modos de reação dos estudantes diante desse contexto.

Canário (2006, p. 7) diz que é recorrente o diagnóstico de que a escola está em crise. A partir da década de 1960, instalou-se o sentimento de que há uma "crise mundial da educação", a ponto de se afirmar que a escola passou, em um espaço de tempo relativamente curto, de "um 'tempo de promessas' para um 'tempo de incertezas'”, cuja explicação reside no fato de que a instituição,

baseada em um saber cumulativo e revelado, [...] é, hoje, obsoleta, sofre de um déficit de sentido para os que nela trabalham, além de ser marcada por um déficit de legitimidade, na medida em que faz o contrário daquilo que promete, originando legiões de insatisfeitos" (Canário, 2006, p. 7).

A crise de sentido e de legitimidade da escola nas sociedades capitalistas, no entanto, não significa que ela está "vazia" de sentido e que seus atores estejam imobilizados e estagnados. Ao contrário, Peregrino (2003, p. 234) afirma que:

Na crise de sentido da escola, ela vai sendo 'preenchida' pelos sentidos diversos, às vezes opostos, contraditórios, dos atores envolvidos em seu fazer cotidiano. Esses fazeres estão referidos a diferentes espaços de produção e de legitimação, configurando, dentro da escola, uma arena de embates provisórios, uma disputa por sentidos para a instituição, contrapondo atores, anunciando projetos.

Pode-se entender, então, que os fazeres que disputam sentidos no interior da escola muitas vezes se apresentam como situações de violência entre alunos e professores, de parte a parte, e que, nesse sentido, cabe um esforço de buscar compreender que mensagens e possibilidades essas situações de violência nos indicam.

\section{Violências contra o patrimônio escolar}

Como se pode observar, na apresentação dos resultados, boa parte da população pesquisada respondeu que a danificação e furto do patrimônio escolar ocorre "sempre" e "às vezes". Como exemplos, podem ser citados: depredações de muros, portas, janelas, fechaduras, carteiras; destruição de livros, de equipamentos audiovisuais e de bens pessoais, como automóveis de professores; furtos de material escolar, vídeo, objetos pessoais, dentre outros.

Essas práticas também são consideradas por Charlot (2003) como modos de manifestação de violência contra a escola, sendo importante, segundo Santos (2009, p. 54), tentar compreender as mensagens escondidas nelas, pois "a violência é um discurso da recusa, ela nasce da palavra e dos gestos emparedados" (Santos, 2009, p. 54).

Para Ruotti (2006), a danificação e o furto de materiais ou equipamentos prejudicam o desenvolvimento das atividades escolares, repercutindo em todos os atores do espaço, podendo produzir um ambiente escolar desvalorizado pelos próprios membros da escola.

A posição dos alunos que, em princípio, parece ser unicamente negativa, destrutiva e de recusa ao ambiente escolar e ao que nele se processa, pode ser também considerada um lugar de protagonismo. Nesse sentido, Peregrino (2003, p. 234) reflete que os alunos:

Confrontados que estão dia após dia com os limites da escolarização desqualificada [...] acabam por ocu- 
par um espaço de particular visibilidade no âmbito das relações que se estabelecem no interior da escola. Acabam por se tornar críticos, por vezes céticos, em relação à instituição. Expressam essa visão em suas ações no espaço escolar.

Cabe à escola oferecer possibilidades de leitura que redimensionem o hegemônico olhar estigmatizante sobre as situações de violência e quem as pratica. Nos termos de Santos (2001, p. 117),

um caminho para uma ação coletiva contra a destrutividade enunciada pela violência, visível nos danos causados ao patrimônio e às pessoas da instituição escolar, repousa na difusão de uma ética da solidariedade, cuja base é o respeito ao outro, exemplificada por uma nova relação entre a escola e os grupos sociais que dela participam, ou que com ela partilham um mesmo espaço social.

\section{Delitos}

No questionário, foi investigada a presença nas escolas dos seguintes delitos: furtos entre os membros da escola, uso e tráfico de drogas e porte de armas, dentre os quais foi destacado pelos participantes apenas o furto entre alunos. Essa realidade de suspeição da presença de delitos na escola permite a reflexão sobre a sensação de insegurança presente hoje nas escolas e do papel da própria escola no mundo contemporâneo.

A escola é historicamente caracterizada como lugar essencialmente socializador. Nos termos de Berger e Luckmann (1973), à família cabe a socialização primária e à escola a responsabilidade pela socialização secundária. Porém, em tempos atuais, a função desta tem sido muito questionada, a tal ponto de haver a avaliação de que "a escola não seria mais representada como um lugar seguro de integração social, de socialização, não é mais um espaço resguardado; ao contrário, tornou-se cenário de ocorrências violentas" (Abramovay \& Rua, 2002, p. 78).

Uma forma de pensar a realidade, que individualiza e patologiza as vivências escolares, permite pensar que os alunos tenham perdido o senso moral, e os professores o senso de autoridade, ou seja, que as violências nas escolas seriam um problema entre velhas gerações desautorizadas e novas gerações desorientadas. Essa forma de pensar, que descontextualiza os problemas escolares, dá mostras de precariedade. No novo modelo capitalista de produção - do capitalismo globalizado -, as violências nas escolas precisam ser contextualizadas a partir das políticas educacionais neoliberais em vigor:

Uma escola de precaríssima estrutura, funcionando na base da subcontratação, lotada de alunos, não é uma escola. É simulacro de escola. Não educa ninguém e nem ensina: contém. Talvez este seja um dos papéis fundamentais da escola que abriga as classes populares hoje: a contenção, dentro de seus limites, de um contingente cada vez maior de jovens (Peregrino, 2003, p. 226).

A autora afirma que talvez o "método" da contenção expresse a eficácia mais perversa das escolas à medida que ensina o lugar social destinado a cada um, porém: “O 'problema' é que os jovens pobres que ocupam nossas escolas não se dispõem com facilidade a aprender essa lição" (Peregrino, 2003, p. 227). Assim, muitas violências podem ser compreendidas como resistência dos alunos ao submetimento institucional de destinar lugares sociais indesejados por eles.

Coimbra e Nascimento (2003, p. 19) analisam características frequentemente atribuídas ao jovem como se fizessem parte de sua natureza. Desde o início do século XX e de forma mais acintosa nos atuais tempos de exclusão neoliberal, fica evidente o processo que constrói a associação da periculosidade, criminalidade e a condição de não humanidade à situação de pobreza. As autoras discorrem sobre diferentes dispositivos sociais que vêm produzindo subjetividades, os quais "têm caracterizado o jovem pobre como perigoso e mesmo como inumano". Porém, "suas resistências deflagram-se cotidianamente, sendo muitas vezes percebidas como fragmentadas, fora dos padrões reconhecidamente organizados, e até mesmo como condutas antissociais, delituosas e, por isso, 'perigosas'” (Coimbra \& Nascimento, 2003, p. 35).

\section{Violências nas proximidades da escola}

Foram apontados como os tipos de violências ou delitos mais comuns nas proximidades das escolas: agressões físicas, roubos, tráfico de drogas e ação de gangues.

Alves (2006) discute que as violências que ocorrem nas proximidades aumentam o sentimento de insegurança nas escolas. Para Ruoti (2006), a presença de situações de risco e violências nas proximidades das escolas sugerem que a ação do poder 
público é insuficiente para proporcionar segurança para os estudantes e demais membros da comunidade escolar, tanto para coibir práticas violentas como para a melhoria das condições de iluminação e infraestrutura dos bairros.

A incapacidade do Estado em proporcionar segurança à sociedade, porém, não é distribuída igualmente. Comunidades mais vulneráveis socialmente têm sido as mais atingidas pela violência. Considerando a multiplicidade de fatores que interagem na produção do fenômeno da violência, Abramovay, Castro, Pinheiro, Lima e Martinelli (2002) recorrem a um "enfoque multidimensional". A partir dele, entendem que:

A violência sofrida e praticada pelos jovens possui fortes vínculos com a condição de vulnerabilidade social em que se encontram nos países latinos-americanos [que] aliada às turbulentas condições socioeconômicas [...], ocasiona uma grave tensão entre os jovens que agrava diretamente os processos de integração social e, em algumas situações, fomenta o aumento da violência e da criminalidade (Abramoway et al., 2002, p. 13-14).

Neste processo, os próprios alunos, e os mais pobres, são os mais atingidos, visto que a violência sofrida e a praticada por eles possui fortes vínculos com a vulnerabilidade social em que se encontram, "dificultando por conseguinte o seu acesso às estruturas de oportunidades disponíveis nos campos da saúde, educação, trabalho, lazer e cultura" (Abramoway et al., 2002, p. 9). Pode-se concluir que a vivência de situações de violência precariza a condição de vida em geral dos que a praticam e dos que a sofrem.

\section{Segurança nas escolas}

Os equipamentos de segurança na escola destacados pela população pesquisada foram: grades, alarmes, muros altos e presença de vigilantes. Essas iniciativas, cada vez mais comuns, são motivadas pelo aumento do número de ocorrências contra o patrimônio da escola (furtos e depredações), especialmente nas madrugadas, finais de semana e feriados, períodos em que as escolas ficam vazias. Em menor medida, são motivadas também pelos riscos à integridade física de alunos e professores. Os equipamentos adquiridos por elas guardam relação com a sua condição econômica, ou seja, elas possuem aqueles que seus recursos financeiros permitem. Muitos desses recursos provêm de contribuições das famílias e de promoções realizadas pelas comunidades escolares. Outro fator que influencia na aquisição ou não de determinado equipamento é o histórico de ocorrências vivenciado pela escola.

A maioria dos participantes afirmou que a presença da polícia na escola acontece raramente. Em geral, tem-se visto que as escolas desejam uma presença maior do aparato militar em seu interior. Sobre essa expectativa, Tondin (2008) afirma que tem causado espanto aos professores a constatação de que a violência que ocorria fora da escola estivesse cada vez mais evidente dentro dos muros o estabelecimento; e que disso decorrem sentimentos de impotência e desistência do "papel de mediadores entre a infância/juventude e o mundo" (p. 215). 0 autor ainda discute que: "Talvez isso explique por que as soluções mais rápidas e fáceis sejam, via de regra, colocar policiamento nas portas das escolas e agentes disciplinares em seu interior como forma de deixar o problema lá fora" (Tondin, 2008, p. 215).

A manutenção da segurança das escolas encontra sérias restrições em um cenário em que as políticas públicas são muitas vezes precárias. No caso do contexto pesquisado, na rede pública estadual de Santa Catarina, tem-se um cenário de restrição orçamentária que precariza as condições do trabalho escolar, o que é coerente com as políticas neoliberais, conforme nos diz Peregrino (2003, p. 222):

Entender as formas particulares de relação entre escola e sociedade nestes tempos de neoliberalismo econômico, de retração de investimentos por parte das políticas públicas, de aumento do controle burocrático sobre as ações e sobre os atores da escola, é um desafio.

Porém, a autora nos alenta ao afirmar que

a escola pública, desqualificada pelas políticas de contenção de gastos na área social, [...] não é, apesar de tudo, um espaço que possa ser definido pela ausência (por tudo aquilo que efetivamente lhe falta). Ela não é um lugar sem significado (Peregrino, 2002, p. 233).

Assim, mesmo em cenário de precariedade, a capacidade inventiva dos professores, alunos e familiares tem superado muitas adversidades, inclusive as relacionadas à falta de segurança nas escolas. 


\section{Considerações finais}

Considera-se que a identificação da presença de práticas violentas em escolas públicas estaduais de Chapecó, a partir do mapeamento realizado e do processo iniciado de restituição das informações produzidas às escolas, permite desencadear avanços nas discussões e análise pelos atores (estudantes, professores, famílias e comunidade) sobre as suas percepções referentes às violências presentes na escola e nas suas proximidades, bem como a busca conjunta de soluções.

Portanto, o mapeamento de práticas violentas pode se tornar um dispositivo de intervenção da psicologia nas comunidades escolares, possibilitando integrar os diferentes atores na busca de produção de conhecimento sobre a realidade vivida e na construção de relações e práticas cooperativas, nas quais estejam presentes o respeito e a ética e que predomine o diálogo em sua mediação. Nesse processo, é importante considerar que conflito contém um potencial de criação de relações sociais, podendo abrir brechas para a invenção na escola e tornar visíveis turbulências e afetações entre os diversos atores presentes no processo pedagógico.

Nesse sentido, o trabalho do psicólogo, na escola, deve buscar a superação dos especialismos, para que as violências não se transformem em mero obstáculo que precisa ser removido por alguém com formação específica para tal, mas que os profissionais da escola, os familiares e os alunos se sintam em condições de enfrentar as adversidades de forma inventiva, implicada e participativa.

Os resultados obtidos por esta pesquisa apontam para a necessidade de elaboração e implementação de políticas públicas que envolvam todos os atores da cena educativa. Buscar, a partir da problematização do cotidiano e de uma efetiva valorização do protagonismo das comunidades escolares, políticas sociais que contribuam significativamente para a construção de uma sociedade mais justa e solidária. Desta forma, as cenas de violência nas escolas podem operar como analisador das políticas públicas sociais, de reflexão sobre os modos como têm enfrentado os dilemas contemporâneos e de que fragilidades e potencialidades elas dispõem nesse enfrentamento.
Notas referentes à pesquisa

A pesquisa foi financiada pelo Fundo de Amparo à Pesquisa da Unochapecó e Artigo 170 do Governo do Estado de Santa Catarina.

Além dos autores, participaram da pesquisa Ana Paula Risson e Juciane Lopes.

\section{Referências}

Alves, R. (2006). As escolas em bairros com altas taxas de violência: A visão dos professores. In C. Ruoti, R. Alves \& V. Cubas. Violência na escola: Um guia para pais e professores (pp. 109-147). São Paulo: Andhep; Imprensa Oficial do Estado de São Paulo.

Abramovay, M., Castro, M. G., Pinheiro, L. C., Lima, F. S., \& Martinelli, C. C. (2002). Juventude, violência e vulnerabilidade social na América Latina: Desafios para políticas públicas. Brasília: Unesco, 2002.

Abramovay, M., \& Rua, M. G. (2002). Violências nas escolas. Brasília: Unesco.

Ansara, S., \& Costa, G. (2009). A violência no ambiente escolar: Contribuições e desafios à Psicologia. In P. F. Vidigal \& D. D’Aurea-Tardeli (Org.). Violência na escola e da escola: Desafios contemporâneos à psicologia da educação (pp. 89-102). São Bernardo do Campo: Universidade Metodista de São Paulo.

Berger, P., \& Luckmann, T. (1973). A construção social da realidade: Tratado de sociologia do conhecimento. Petrópolis: Vozes.

Canário, R. (2006). A escola tem futuro?: Das promessas às incertezas. Porto Alegre: Artmed.

Charlot, B. (2002). A violência na escola: Como os sociólogos franceses abordam essa questão. Sociologias, 4(8), 432-443.

Coimbra, C. M. B., \& Nascimento, M. L. (2003). Jovens pobres: 0 mito da periculosidade. In P. C. P. Fraga \& J. A. S. Iulianelli (Org.). Jovens em tempo real (pp. 1937). Rio de Janeiro: DP\&A.

Lourau, R. (1993). Análise institucional e práticas de pesquisa. Rio de Janeiro: UERJ.

Michaud, Y. (1989). A violência. São Paulo: Ática. 
Paula, F. V., \& D’Aurea-Tardeli (2009). Violência na escola e da escola: Desafios contemporâneos à psicologia da educação. São Paulo: Universidade Metodista de São Paulo.

Patto, M. H. S. (2005). Violência nas escolas ou violência das escolas? In M. H. S. Patto. Exercícios de indignação: Escritos de Educação e Psicologia (pp. 29-40). São Paulo: Casa do Psicólogo.

Peregrino, M. (2003). E o bonde abalou! Contenção, juventude e embate nas escolas do Rio. In P. C. P. Fraga \& J. A. S. Iulianelli (Org.). Jovens em tempo real (pp. 221-236). Rio de Janeiro: DP\&A.

Rocha, M. L. (2000). Educação em tempos de tédio: Um desafio à micropolítica. In E. Tanamachi, M. Proença \& M. L. Rocha (Org.). Psicologia e educação: Desafios teórico-práticos (pp. 185-207). São Paulo: Casa do Psicólogo.

Ruoti, C. (2006). Conflito e insegurança escolar nas zonas leste e sul dos municípios de São Paulo. In C. Ruoti, R. Alves \& V. Cubas. Violência na escola: Um guia para pais e professores (pp. 55-102). São Paulo: Andhep; Imprensa Oficial do Estado de São Paulo.

Ruoti, C., Alves, R., \& Cubas, V. (2006). Violência na escola: Um guia para pais e professores. São Paulo: Andhep; Imprensa Oficial do Estado de São Paulo.
Santos, J. V. T. (2001). A violência na escola: Conflitualidade social e ações civilizatórias. Educação e Pesquisa, 27(1), 105-122.

Sebenello, D. C. (2009). Violências e escola: Discursos e práticas do cotidiano de uma escola estadual. Trabalho de Conclusão de Curso, Universidade Comunitária da região de Chapecó, Chapecó.

Santos, J. V. T. (2009). Violências e conflitualidades. Porto Alegre: Tomo Editorial.

Souza, M. P. R. (2006). Políticas públicas e educação: Desafios, dilemas e possibilidades. In L. S. Viégas \& C. B. Angelucci (Org.). Políticas Públicas em Educação: Uma análise a partir da Psicologia Escolar (pp. 229-243). São Paulo: Casa do Psicólogo.

Sposito, M. P. (1998). A instituição escolar e a violência. Cadernos de Pesquisa, 104, 58-75.

Tondin, C. F. (2008). Violências nas escolas e territórios educativos. In I. S. Bonamigo, C. F. Tondin, \& K. Bruxel. (Org.). As práticas da psicologia social com(o) movimentos de resistência e criação (pp. 207-216). Porto Alegre: Abrapso Sul. 